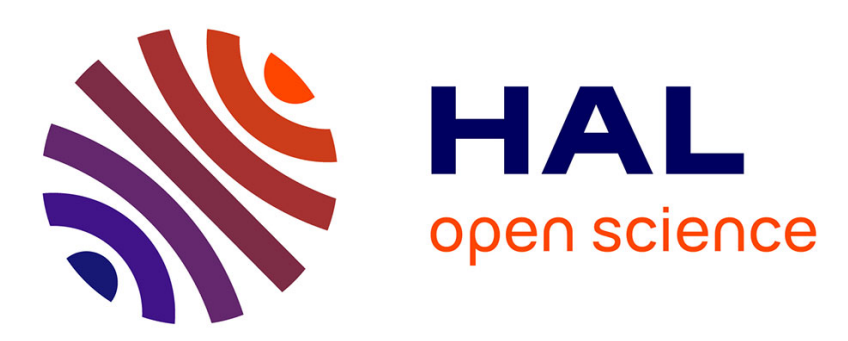

\title{
About adopting a systemic approach to design connected embedded systems: A MOOC promoting systems thinking and systems engineering
}

Claude Baron, Brigitte Daniel-Allegro

\section{- To cite this version:}

Claude Baron, Brigitte Daniel-Allegro. About adopting a systemic approach to design connected embedded systems: A MOOC promoting systems thinking and systems engineering. Systems Engineering, 2020, 23 (3), pp.261-280. 10.1002/sys.21513 . hal-02308315

\section{HAL Id: hal-02308315 \\ https://hal.laas.fr/hal-02308315}

Submitted on 10 Oct 2019

HAL is a multi-disciplinary open access archive for the deposit and dissemination of scientific research documents, whether they are published or not. The documents may come from teaching and research institutions in France or abroad, or from public or private research centers.
L'archive ouverte pluridisciplinaire HAL, est destinée au dépôt et à la diffusion de documents scientifiques de niveau recherche, publiés ou non, émanant des établissements d'enseignement et de recherche français ou étrangers, des laboratoires publics ou privés. 
About adopting a systemic approach to design connected embedded systems: A MOOC promoting systems thinking and systems engineering

\author{
Claude BARON \\ LAAS-CNRS, Université de Toulouse, CNRS, INSA \\ 7 avenue du Colonel Roche, 31500 Toulouse, France \\ claude.baron@laas.fr \\ Brigitte DANIEL-ALLEGRO \\ Systems Thinking and dependability senior expert \\ 31620 Castelnau d'Estrétefonds, France \\ brigitte.daniel.allegro@gmail.com
}

\begin{abstract}
A connected embedded system is a complex system that integrates hardware and software elements and has real-time interactions with its environment. Developing such a system requires having a systemic approach, based on Systems Thinking and Systems Engineering. Systems Thinking demonstrates the need of adopting an interdisciplinary approach (not only technology focused but also considering societal or regulatory commitments, to name a few), that is essential to explore the whole embedded systems field. Systems Engineering enables learners acquiring a method that provides the means to set up a consistent design and management plan that fully integrates a product development. This paper describes how a MOOC has been designed and produced to promote the use of a systemic approach when developing connected embedded systems. The MOOC uses different case studies in order to progressively introduce a way to develop specific System Thinker's skills for identifying and solving a variety of problems raised during the design of a connected embedded system. Launched in 2016, it attracted more than 10.800 learners in less than 2 years. What led to such a success is certainly because the team that created the MOOC experienced a collaborative and integrative approach, namely a systemic approach, that also revealed its benefits in this educative project.
\end{abstract}

Keywords - System thinking, Multidisciplinary design, System development, Cyber-Physical systems

\section{INTRODUCTION}

An embedded system is usually defined as an autonomous real time electronic and computerized system specialized in a specific task [1]. According to the report [2], an embedded system is "a computerized, specialized and autonomous system, which constitutes an integral part of a larger system; it combines hardware and software". The adjective "embedded" means deeply integrated, reflecting the non-visible side of such equipment. Its resources are usually limited by the host that embeds it (in size, mass, energy, autonomy or means of communication for instance).
A connected system includes a system of identification and collection of data, a data transmission system with a 'smart' application and an interface to drive the application. In theory, any object can be connected; it is the Internet of things (IoT). The Internet of connected objects represents the exchange of information and data from devices of the real world to the Internet [3].

[2] points out that connected embedded systems are at the crossroads of several cutting-edge technologies. They rely today on the capabilities of "cloud computing" and "big data". Some developments are clearly market trends; among these, the Internet of Things is the most clearly identified one. Market opportunities and applications of connected embedded systems are increasingly numerous (autonomous car, factory of the future, connected headset for surgeons, etc.).

However, challenges, particularly in terms of safety, must still be addressed. That is why it is important to know how to assess the safety of such systems, and to consider the other different attributes of dependability also (reliability, availability and maintainability) to integrate these challenges throughout the system life cycle: from design, development and operation of the system, or even until his removal from service (cf. Fig 1).

\begin{tabular}{|c|c|c|c|c|c|}
\hline \multirow{2}{*}{$\begin{array}{c}\text { Concept } \\
\text { Stage }\end{array}$} & \multirow{2}{*}{$\begin{array}{l}\text { Feasibility } \\
\text { Stage }\end{array}$} & \multirow{2}{*}{$\begin{array}{c}\text { Development } \\
\text { Stage }\end{array}$} & \multirow{2}{*}{$\begin{array}{l}\text { Production } \\
\text { Stage }\end{array}$} & $\begin{array}{l}\text { Utilization } \\
\text { Stage }\end{array}$ & \multirow{2}{*}{$\begin{array}{c}\text { Retiremen } \\
\text { Stage }\end{array}$} \\
\hline & & & & $\begin{array}{l}\text { Support } \\
\text { Stage }\end{array}$ & \\
\hline
\end{tabular}

Fig. 1. A classical System Life Cycle Model

Due to the increasing complexity of systems, it is mandatory to have the stakeholders involved in the system development able to master rigorous validation and design methods [2]. The systemic approach strongly contributes to this objective by seeking to understand the relationships of complex systems with their environment, their functioning and their mechanisms, for optimizing their life cycle. According to Mitchell [4], currently there is no single science of complexity nor single theory about complexity. However, Mitchell tried to identify common properties of complex systems, namely, a complex collective behavior, treatment and transmission of information, adaptation through learning or evolution. We consider that the 
connected embedded systems share the properties of complex systems.

This article reflects an 18 months' work (January 2015 to June 2016) of a team of teachers, researchers, consultants and industrial experts from different disciplines, all convinced of the benefits of the systemic approach for designing connected embedded systems. It resulted in the launch of the MOOC "Embedded and connected systems" in July 2016.

Beyond promoting a systemic approach, three scientific, pedagogical and educational objectives led our engagement in this project. The first was to share our viewpoints on connected embedded systems, thus providing teachers with a common knowledge base for presenting and teaching connected embedded systems in their operational context. The second objective was to use a pedagogy based on case studies to illustrate how to address such systems with method and rigor guided by the system thinking philosophy and using systems science and systems engineering. The third objective was to disseminate the results to a large audience by spreading a MOOC (Massive Open Online Course) available over the internet, that can be followed by a large number of people [5].

This MOOC [6] offers a general presentation of embedded and connected systems in their operational contexts; its scientific goal is to lay the foundations of such systems and besides to promote System thinking.

Overcoming a traditional presentation divided by discipline such as computer science and networks, electronics, automation, or mechanics, the MOOC suggests a new interdisciplinary teaching approach. Firstly, it is opened to other disciplines (mobilizing scientific and technical knowledge, but also legal, economic and other societal knowledge); secondly, it integrates cross-cutting analysis (such as dependability) to face the challenges identified in [2]. It is very innovative by using the structuring feature of the systemic approach which allows an integration of multiple areas and by pointing out various trades and know-how from the outset. The MOOC was opened twice; the first session was hold in 2016 July and the second one in 2017 October. It met a wide audience, considering that it is a French speaking course, with 4722 registrations in 2016 and 6116 in 2017.

Section 2 of this paper introduces the systemic approach. Section 3 presents the MOOC; it defines the purpose, the objectives and the structure of the MOOC which is organized around three case studies. Sections 4, 5 and 6 detail each case study. Section 7 makes a synthesis focusing on the pedagogical results. Section 8 concludes on one hand on the value of the systemic approach and on the other hand on the educational opportunities offered by the format of MOOC for any teacher who would like to adapt its practices to this new medium.

\section{A Systemic Approach of Connected EMBEDDED SYSTEMS}

By their very nature, connected embedded systems exchange information between a multitude of virtual or real agents in a highly changing context. For this reason, it is required to implement a systemic approach that is based, on one hand, on the System Thinker who observes and grasps the overall situation to understand its complexity [7], and on the other hand, on Systems Engineering [8] to implement the engineering of the systems in an interdisciplinary and collaborative way.

Praxis and more specifically Systems Praxis can help to encompass the links between Systems Thinking, Systems Engineering and Integrative Systems Science [9]. Praxis is defined as the process by which a theory, lesson, or skill is enacted, embodied, or realized [10]. Systems Praxis refers to the entire intellectual and practical endeavor of creating holistic solutions to complex system challenges [11]. A joined collaboration of ISSS (International Society for the Systems Sciences), IFSR (International Federation of Systems Research) and INCOSE (International Council of Systems Engineering) resulted in defining the Systems Praxis Framework (cf. Fig. 2). This framework provides a common map wherein each researcher or practitioner can recognize and appreciate their complementary roles played in the complex process of systems praxis [11].

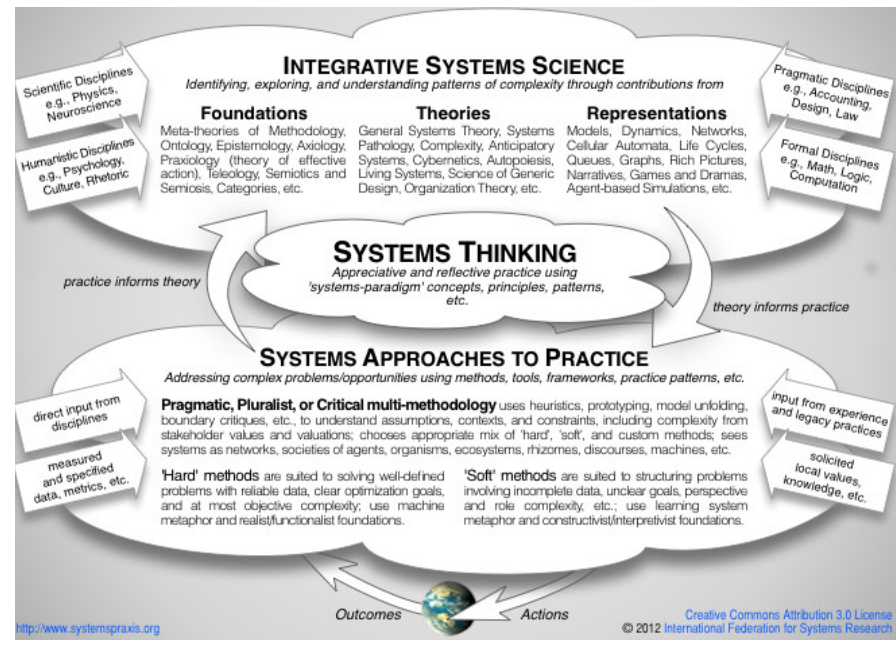

Fig. 2. The Systems Praxis Framework [11]

The Systems Praxis Framework points out the key role of Systems Thinking as being the core integrative element of the framework. Systems Thinking binds the foundations, theories and representations of systems science together with the pragmatic, "hard", and "soft" approaches of systems practice.

Integrative Systems Science has a very wide scope and is divided into three broad areas:

- Foundations, which help us to organize knowledge, learning, and discovery;

- Theories about systems, identifying patterns abstracted from and applicable across domains and specialties;

- Representations, which allow insight into and communication about systems and their contexts by describing, exploring, analyzing, making predictions.

Integrative Systems Science allows us to identify, explore, and understand patterns of complexity relevant to a problematic.

Systems Approaches to Practice draw on integrative systems science to address complex problems and opportunities. Systems Approaches to Practice aim to produce desired outcomes while being mindful of unintended consequences. 
System Thinking binds the two together through appreciative and reflective practice using systems paradigm concepts, principles, and patterns; and, finally, observing the results of systems practice, System Thinking enhances both practice and theory.

\section{A. System Thinking}

When we speak of System Thinking, we should not forget the person who thinks and acts, trying to understand and to face any situation. So, paying attention to his/her attitude will help to identify the exclusive skills of system thinkers. The guide [Daniel-Allegro, 2014b] describes the attitude of the System Thinker, who seeks to understand complex situations, events or changes in their environment, and System Thinking as "the ability to identify and understand as a whole, the structure of a system as well as its behavior and its relationship with its environment".

These attitudes reveal the readiness of the mind and body of the System Thinker whose intention is to understand a situation or to act. They reflect his/her knowledge, know-how and experience, their emotional reactions and state of the mind towards a situation. The System Thinker dives into past events and projects themselves into the future in order to understand a present-day situation while considering the potential variety of outcomes and consequences. The System Thinker "Perceives", "Detects the Influences", "Understands the System", "Reassesses". Practicing these attitudes allows among other things gaining a better insight into decision making and into acting (cf. Fig. 3).

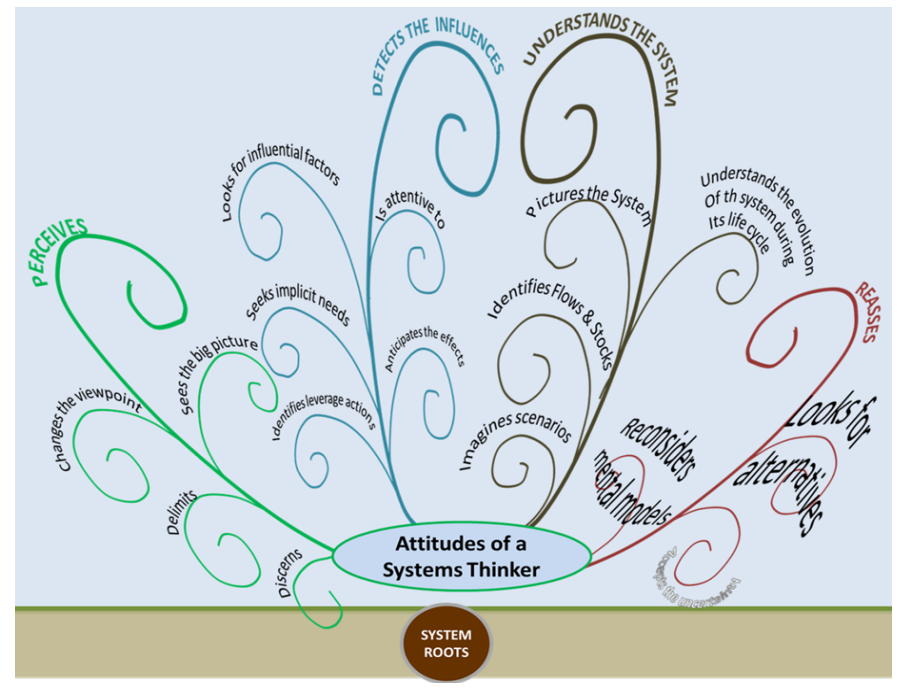

Fig. 3. Attitudes of a System Thinker [12]

A number of system concepts underpin the System Thinker's attitudes and contribute to defining the so called "system roots" (cf. Fig. 4). In [12]'s perspective, the concept is a mental representation which is neither true nor false but has been found to be useful to make connections with Integrative Systems Science. The main roots deal with the concepts of "Context", "Purpose", "Behavior", "Relationships", "Structure" and "Togetherness". It allows addressing a mechanical viewpoint as well as a teleological viewpoint onto systems.

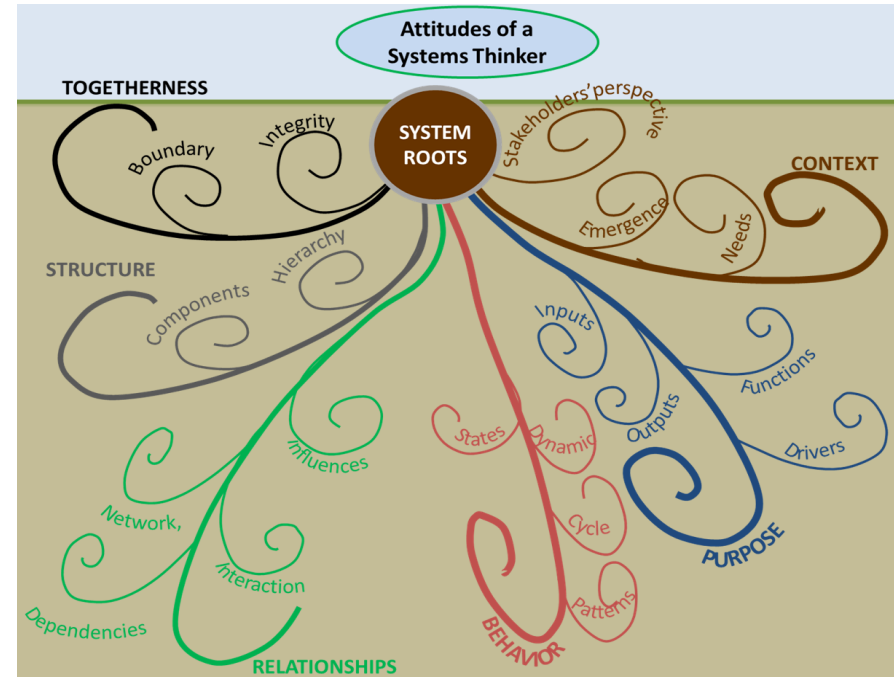

Fig. 4. System roots underpinning System Thinker's attitudes [12]

The Systems tree model visualizes the attitudes of the Systems Thinker and the system concept roots in a mind map that looks like a tree. In fact, the branches (attitudes) and the roots (system concepts) are fractal in nature and it is expected that over time they will adapt and grow from the main branches and the main roots (cf. Fig. 5).

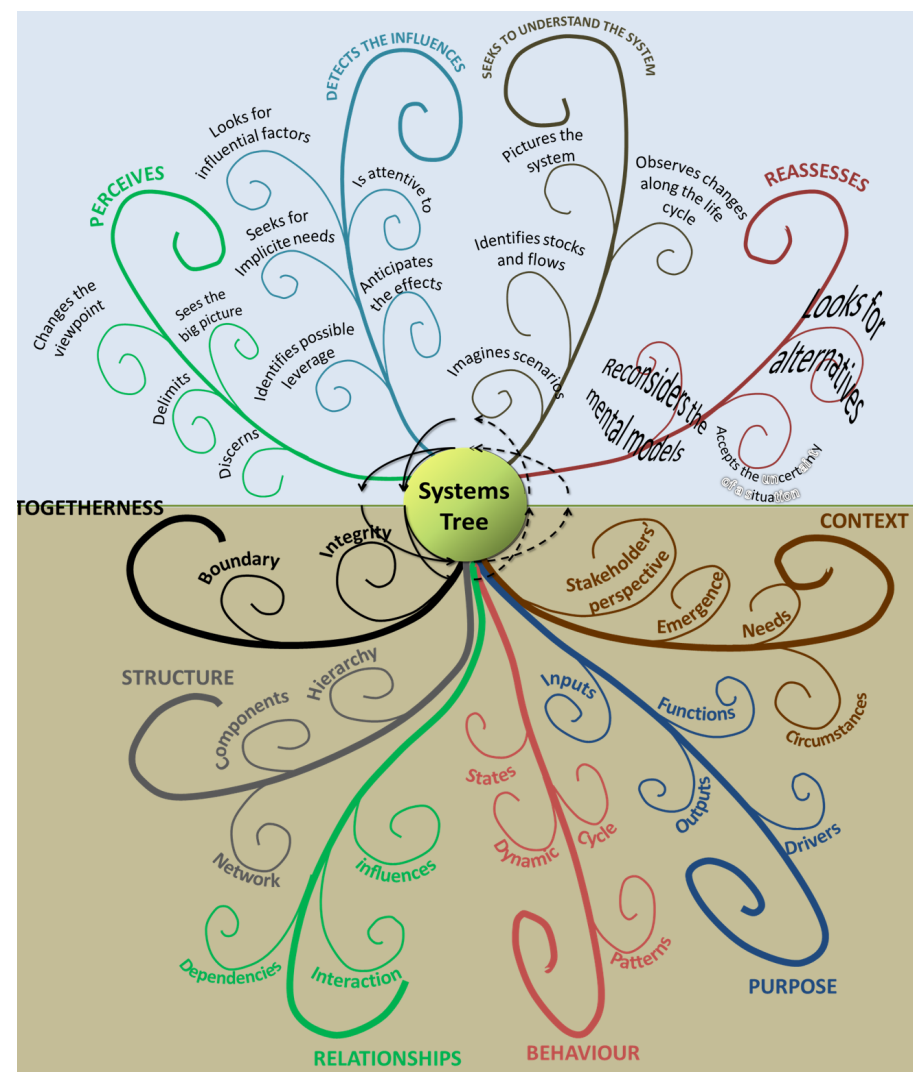

Fig. 5. The Systems Tree [13] 


\section{B. Systems Engineering}

Systems Engineering (SE) is defined as "a collaborative, interdisciplinary approach, based on science and experience, which includes activities to design, develop, evolve and verify a set of processes, products and skills providing a globally optimized solution to identified needs that are acceptable for the environment" [14]. SE addresses the overall ISO/IEC/IEEE 15288 processes [15]: “Agreement Processes, Project Processes, Technical Processes, Organizational Project Enabling Processes" (cf. Fig. 6).

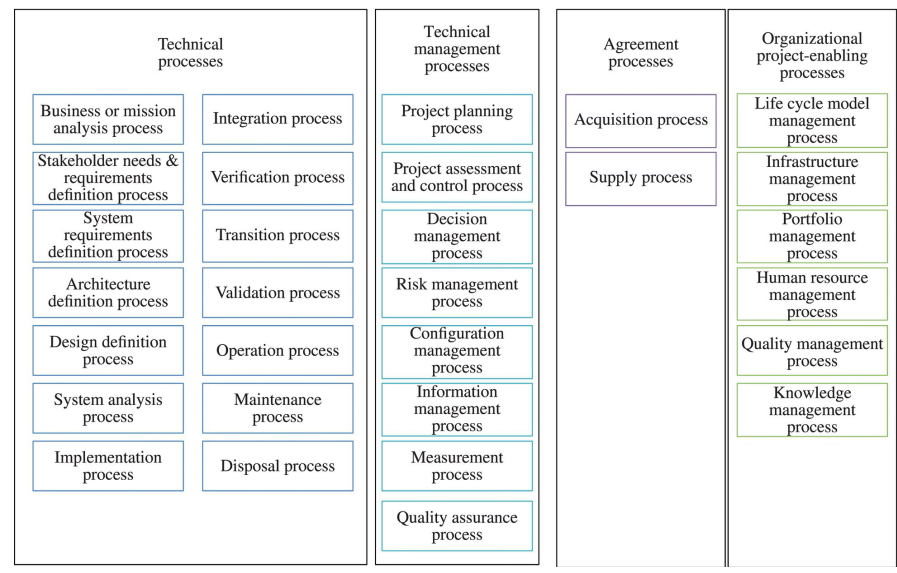

Fig. 6. System Life Cycle Processes from ISO15288

The systemic approach, integrating System Thinking and Systems Engineering, based on Integrative Systems Science, is vital to properly addressing complex systems. It is a collaborative approach in the context of an extended enterprise where are mastered the management of engineering activities such as the analysis of the market, the understanding of the missions and operational requirements, the definition of a coherent architecture, as well as the management of quality, traceability, changes and configuration, production, acquisitions, etc. [16].

To sum-up this introduction, System Thinking is the cornerstone to identify and characterize a situation on which the System Thinker will act by identifying the dynamic of a situation, its evolution in a changing context and the key factors (even low signals) which could influence the situation. The System Thinker is able to conceptualize and represent a situation into a situation system to work with. Systems Engineering deals with how to engineer, how to organize and to manage the situation system in a collaborative way.

\section{MOOC PRESENTATION}

This section exposes the purpose and objectives of the MOOC and describes how it is organized.

\section{A. Purpose and Objectives}

The purpose of this MOOC is to teach a systemic approach to the design of connected embedded systems to answer to the challenges of safety and more widely dependability highlighted in the introduction. It consists of understanding a complex situation and featuring the problems that arise as a result of the interaction of such systems with their environment. The difficulties come from the interweaving of several sectors of activities and disciplines that it is essential to grasp in a comprehensive approach. It is important to be able to identify and characterize the economic, regulatory, societal and technological factors in the environment that influence the design and use of the system in all along its life cycle. Another challenge is to precisely find and characterize all the actors also called 'stakeholders' and their level of intervention in the life cycle (customers, suppliers, contributors playing different roles, opponents, sponsors, governmental, security, qualifying or healthcare organizations...). Omission of stakeholders may have a disastrous impact on a project. For instance, if environmental standards banning the use of products that could be harmful to the environment are not considered, the system will have to be re-designed and the contracts with the suppliers will have to change.

The MOOC objectives are to get the learners across the need to integrate these different ways of thinking and disciplines in the development of connected embedded systems and to show how to navigate through different levels of abstraction, from the most general to the most detailed, and from modeling to a product. To achieve these objectives, the MOOC offers an innovative way to address these systems by a systemic approach, integrating socio-economic and scientifictechnological aspects, thus, removing barriers between disciplines and providing a guiding method as well.

Furthermore, the MOOC relies on several case studies which are representative of different fields of application of connected embedded systems. These different illustrations are powerful to develop a learning progression in the perception and analysis of situations with a systemic approach. These examples enable sharing knowledge and general practices on connected embedded systems and they introduce tracks to inspire learners to explore or deepen certain fields of application.

\section{B. Structure}

The structure of the MOOC is designed to stimulate a progressive learning. It is based on three illustrative case studies chosen in different fields of application, smart housing, agriculture and aviation (cf. Fig. 7). These case studies introduce different systemic concepts. They also enable sharing knowledge and general practices on connected embedded systems. They have been specifically elaborated to illustrate the MOOC by using existing embedded connected systems or innovative ones (such as the connected smoke detector which was not yet marketed in 2015). 


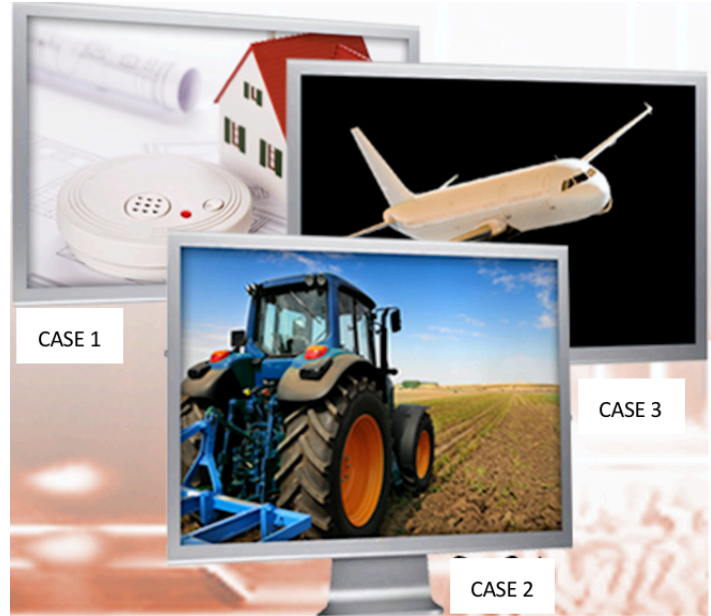

Fig. 7. The three case studies

Case studies are developed according to the same generic methodological framework, inspired by the ISO/IEC/IEEE 15288 [15]. The MOOC provides means to implement these processes through the integration of Systems Thinking and Systems Engineering. It guides the learner via predefined steps, focusing on the early stages of system life cycle: design and development. This framework is essential to point out all the stakeholders that play a role in any stage of the life cycle of the connected embedded system. It focuses on the boundaries of the system as well as the stakeholders, and helps identifying, during the life cycle analysis, the relationships between the actors and the links with the processes of the ISO/IEC 15288.

Each case study starts with a comprehensive approach of a given situation, practicing System Thinker's attitudes to clarify the situation, the System of Interest of the case study, to delimit the perimeter of the system and its boundaries, to highlight its relationships with external systems as well as with the stakeholders, all along the life cycle of the system. It results in a proposition of a so-called Context Diagram

In terms of know-how acquisition, the selected illustrative cases offer a progression along three axes: the maturity of the processes, the level of industrialization and the dependability (cf. Fig. 8).

1. With respect to the maturity of the processes, we refer to CMMI to distinguish maturity levels: we start with a first case study requiring no formalization of the processes, then consider the case of a marketed system where processes are defined, to finally address the case in the avionics field which requires managed and optimized processes.

2. Regarding the level of industrialization, we start with the case of an individual project to assemble at home various components bought off the shelf in order to make a connected smoke detector prototype, then we consider the case of a project for a navigation aid system in an agricultural vehicle developed by a small company, to finish with the case of an avionics project held by a large industrial group.

3. Dependability is addressed in its different disciplines (usability, maintainability, reliability, availability, safety) through the three cases, with emphasis on specific discipline according to the cases. For example, the case of the smoke detector intuitively addresses reliability and maintainability, while the case of the avionics system emphasizes availability and safety.

$$
4
$$

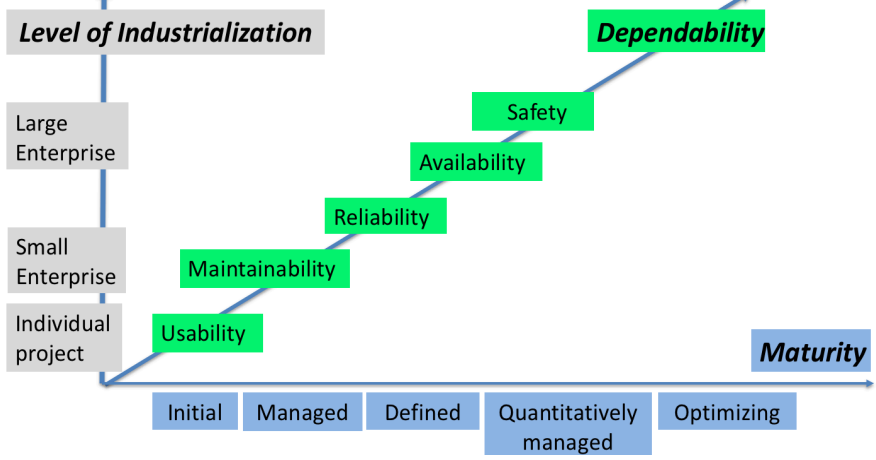

Fig. 8. Learning progression along three axes

\section{Focus on the generic framework}

The MOOC provides means to implement systems engineering processes through the integration of Systems Thinking and Systems Engineering. It relies on a generic framework that guides the learner through following several dedicated steps.

\section{System of Interest and Context Diagram}

The Context Diagram described in the Fig. 9 is a first step to visualize the key elements and their links in their environment. In the context of the CES, four types of stakeholders have been identified ('Involved in the product development', 'Interested by the use and the exploitation of the CES', 'Potentially affected' and 'Third party bodies'). The external systems have been classified into three types (Embarking system, External systems, Project management system). All these external systems are embodied by other stakeholders who play a role in the life cycle of the CES and which must be addressed.

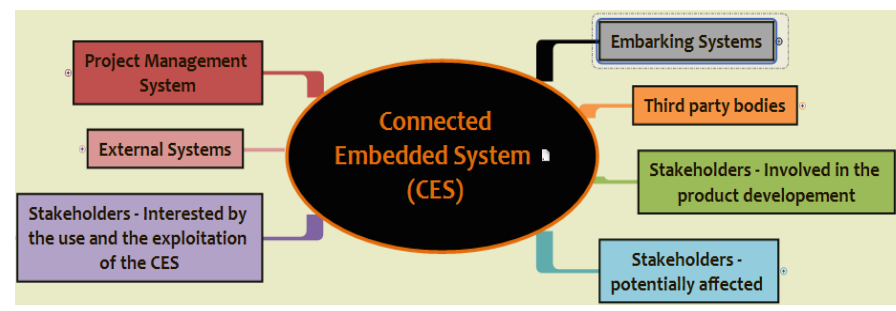

Fig. 9. Preliminary generic Context Diagram

\section{System of Interest (SoI) during the System Life Cycle}

As the SoI encompasses the whole System Life Cycle, Systems Thinking is highly recommended at the earliest stage of the Concept Stage in order to have a complete view of the flow of information exchanged by all the stakeholders involved throughout the whole Life Cycle.

It is essential to understand, as Lawson [17] comments, that "the System of Interest evolves from need to concept to reality in the form of products and services". The Fig. 10 illustrates this evolution of the SoI, which can be described as a "Defined 
Abstract Systems, to Defined Physical / Human Activity Systems, when they become a Product that is instantiated for utilization".

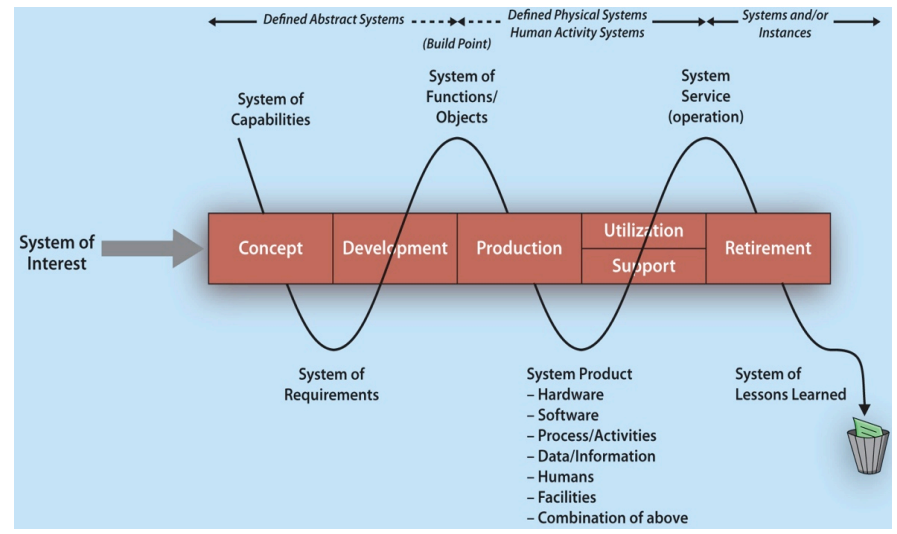

Fig. 10. Life Cycle Transformations (SoI Versions) [Lawson, 2010]

In practice, a context diagram is defined for each life cycle stage and then the global context diagram integrates all the key elements in relation with the system with their flow of exchanged data / information (cf. Fig. 11).

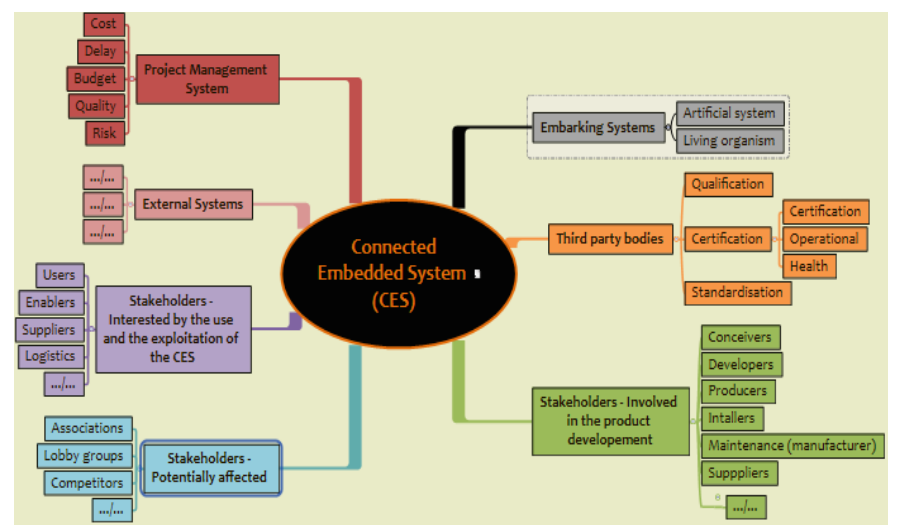

Fig. 11. Generic Context Diagram

This generic framework is essential to point out all the stakeholders that play a role in any stage of the life cycle of the connected embedded system. They must be associated as soon as the concept emerges, during the concept / feasibility stage of the project. As far as Connected Embedded Systems are concerned, the "Embarking system" could be an artificial system (as an airplane embarking an auto pilot, for instance) or a living organism (as a human embarking a connected watch, for instance).

Think of the many projects that did not address the retirement or recycled stage and the issues that people faced without any easy solution decades after utilization. For example, think of the accumulation of the space junks that human activity generates during the last decades.

\section{Relationships between processes}

This generic framework, focused on the boundaries of the system as well as the stakeholders, helps identifying, during the life cycle analysis, the relationships with ad-hoc processes mentioned by the ISO/IEC 15288: Agreement processes (patent and intellectual property management for instance), Technical processes, Technical Management processes, Organizational Project-Enabling processes (infrastructure management or quality management for instance). The cornerstone is how to integrate dynamically these processes in an efficient management plan. [17] gives an example through a model which "portrays a situation in which an acquiring company forms an agreement with a supplying company for delivering products or services" (cf. Fig. 12).

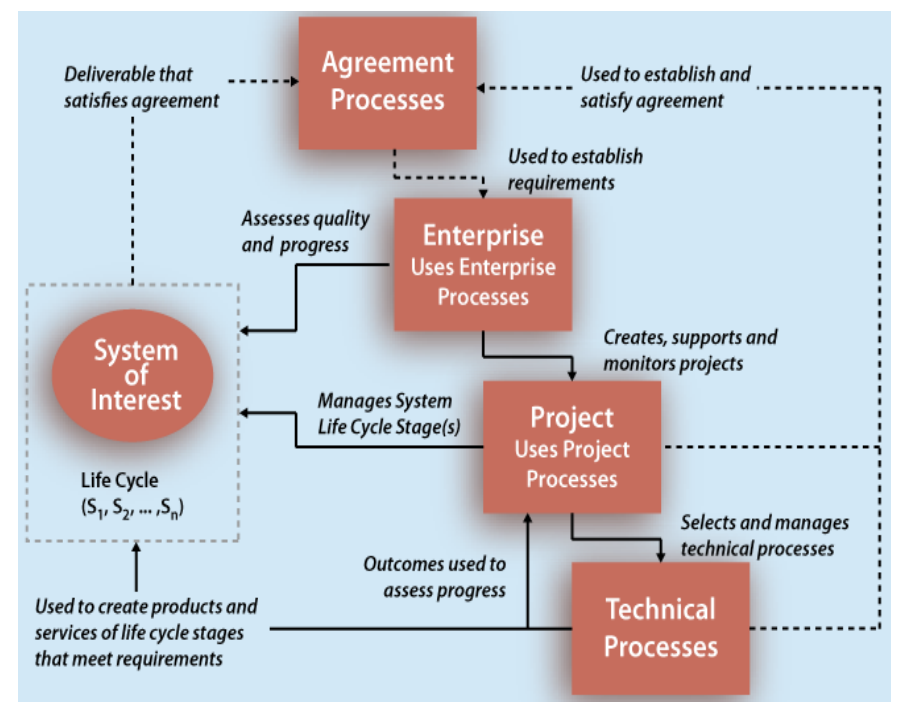

Fig. 12. Example of integration of the ISO/IEC 15288 processes - A Model for the Acquisition of System Products and Services [17]

\section{Organization of the learning modules}

The MOOC offers a series of learning modules, consisting of different types of resources, such as videos, scripts and supporting material for presentation in the form of slides as well as additional resources (documents, links, glossaries, etc.)..

The MOOC includes a total of 16 interviews, 47 videos with a cumulative time of $7 \mathrm{~h} 30$, the participation of 15 experts from specific disciplines (such as energy, communication networks or intellectual property) or transverse disciplines (such as dependability).

We set up and facilitated 4 distinct forums to exchange with learners and for learners to exchange among themselves:

- a technical forum, centralizing all technical questions concerning the platform, video formats, etc.

- three discussion spaces differentiated according to the case study.

\section{E. Targeted audience}

The MOOC was initially designed for continuing education. However, it addresses a wide audience, which is perfectly consistent with the FUN (France Université Numérique) platform dissemination objectives. It aims in particular at:

- Technicians, managers and engineers in the industry, 
- Teachers, researchers, doctoral students and students in initial training.

- Job seekers in phase of conversion or training request,

- Retirees,

- Or anyone curious to discover the world of connected systems, regardless of their educational qualification.

\section{F. Evaluation}

Evaluation is based on self-assessments and a final writing exercise, leading to the delivery of a certificate if successful. At the end of each case study a quiz is proposed in order to evaluate the acquired knowledge. It allows everyone one to determine their level of understanding and appropriation of the concepts developed in the case study. The quiz allows two attempts before answering the questions. Learners have the opportunity to review some videos or read the scripts if they fail on the first attempt. A final peer review exercise may be proposed in addition. It consists of a transposition of a topic taken from the case studies. At the end of the evaluations, if the conditions for success are reached, a certificate is delivered to the learner for assessing their progress throughout the learning.

\section{A CONNECTED SMOKE DETECTOR}

The first case study belongs to the domain of smart housing. The main function of the system to design consists in detecting smoke in a house and alerting.

\section{Setting the situation}

The situation is the following: the French law No. 2010-238 from March $9^{\text {th }}, 2010$ makes it mandatory to install smoke detectors in every home. Joe, a conscientious citizen, thinks about buying and installing one in order to comply with the legislation. He buys a smoke detector in a store and installs it at home. Despite this precaution, his house burns; a fire caused by a faulty toaster broke out while he was at work. In this situation, the smoke detector worked well, but no one reacted because nobody was alerted, and Joe's house burnt. The situation is animated using a cartoon as illustrated in Fig. 13.

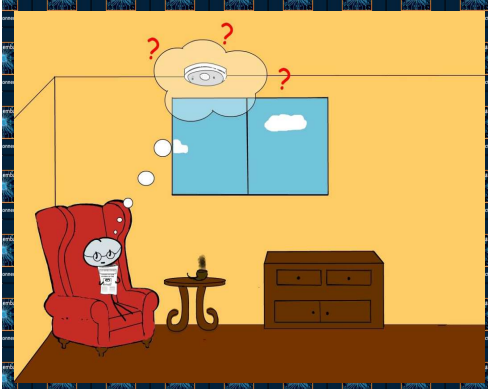

Fig. 13. Context of case study $n^{\circ} 1$

\section{Issues to be addressed and approach}

As it is an individual project, no process is formalized, dependability is approached through usability (cf. Fig. 14).

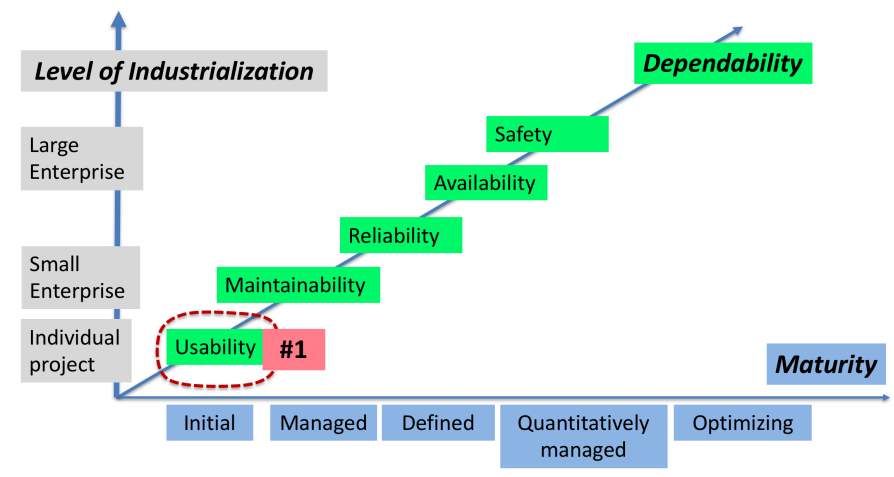

Fig. 14. Learning objectives of the case study $n^{\circ} 1$

Nevertheless, this individual project needs to define the available budget and the associated cost. To make an estimation of the costs, Joe must define the external systems connected to the smoke detector (one or two mobile phone) and the external system enabling the functioning of the smoke detector (energy supply, communication means, installation mounting).

He lists a few stakeholders such as third-parties (to comply with the legislation), suppliers involved in tooling, electronics, maintenance (battery), a social network on smoke detectors, people interested in the use of the connected detector such as the housing insurer. Joe has in mind a kind of Context Diagram as described in Fig. 15.

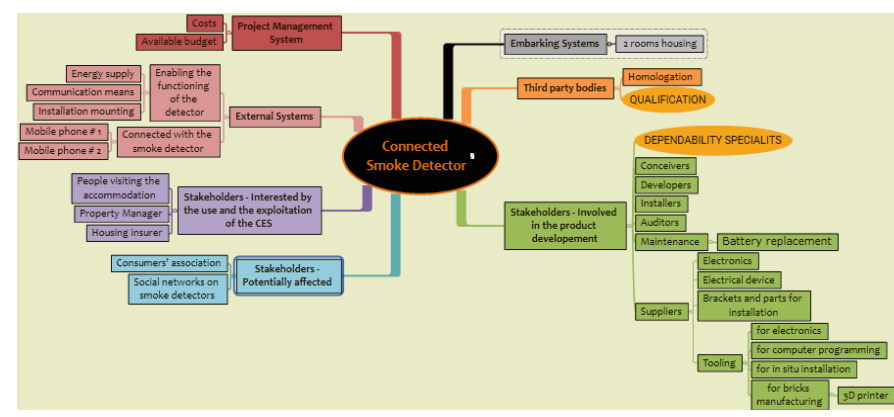

Fig. 15. Context Diagram of the Connected Smoke Detector

What Joe experienced with the fire in his house due to his inexperience in CES helped him to open his eyes, to reflect on his responsibilities in this fire and to address the situation in a larger context to avoid another damage, if possible. Designing the Context Diagram of the Connected Smoke Detector was a way to identify the external systems, including a distinction between the systems enabling the functioning of the detector (such as energy supply, communication means, installation mountings) and those connected with the smoke detector (such as one or several mobile phones). At this stage, almost naturally some questions and decisions to make arise.

So, the question we consider is to connect the smoke detector in order to make it intelligent, able to alert someone remotely in case of smoke detection. As this device does not yet exist, Joe decides to design and manufacture himself a connected smoke detector answering his specific need, to alert him in case of smoke. He wonders: What components do I need? Where to get them or can I make some by myself? How much will it cost me? Do I need specific tools? How do I 
organize my work to design and assemble the system? How can I be sure that the detector will work when needed and that it will not inadvertently ring without a reason? How to be sure I have thought of everything in my project? Will my insurance refund me in case of fire?

This case offers the pretext to address several specific analyses, such as the energy supply of the system, its ergonomics and the raw materials used for its manufacturing.

Power supply. The detector requires energy to power three of its components: the electronic smoke sensor, the audible alarm generator and a LED indicating that the detector is on. The simplest solution for an individual home is to store this energy in an electrochemical cell. Other solutions are possible, such as a wired electrical network, which is rather used in industrial or professional purpose buildings. Ambient energy recovery techniques, such as light energy, would not be suitable.

Ergonomics. With a new cartoon, we show that the detector push-button must be easily reachable once the detector is placed on the ceiling.

Raw materials. We show the importance of using materials that are resistant to high temperatures, dust and water, to make this system robust against adverse external conditions.

Several tracks for deepening the factory of the future, the challenges facing society, jobs in the digital sector, etc. are provided at the end of this case study.

\section{E. Demonstration of the interest of a systemic approach}

The educational objective here is to raise the awareness that the system engineering approach encompasses the design, the development and the use of a technical products (in this case an embedded connected system). It requires taking into consideration a set of several parameters:

- Technical parameters: which technology to use? at what level to ensure the required functioning?

- Economic parameters: to make or to buy? at which cost? what are the benefits of developing it oneself?

- Project management parameters, mainly focused on design development and manufacturing: what is the deadline to have the detector operational?

Beyond these traditional questions, in order to raise the awareness on System Thinking, the awareness of the overall situation is to explore other dimensions such as:

- Spatial-temporal parameters: maintenance, withdrawal service,

- Societal parameters: acceptance of the product by the end user as an effective solution to the expressed problem,

- Ecological parameters: management of the product withdrawal, recycling,

- Legal parameters: qualification criteria and process, regulation, applicable norms and standards.

By reassessing the situation (cf. System Tree, System Thinker's attitudes) the learners develop self-reflexivity, reconsider their mental model and look for alternatives solutions. By trying to understand the "situation system" the learners develop their ability to picture the system, to imagine scenarios or to observe the changes along the life cycle [18].

\section{AN INDUSTRIAL SYSTEM OF NAVIGATION AID EMBEDDED IN AGRICULTURAL VEHICLES}

The second case study belongs to the agricultural sector.

\section{F. Setting the situation}

We move to the case of a small or medium company (SME) employee who has to design, manufacture and market a computer to support navigation, embedded in an agricultural vehicle (cf. Fig. 16). This system will be sold to be integrated into different vehicles, regardless of the agricultural mission (plowing, weeding, mowing, spraying...).

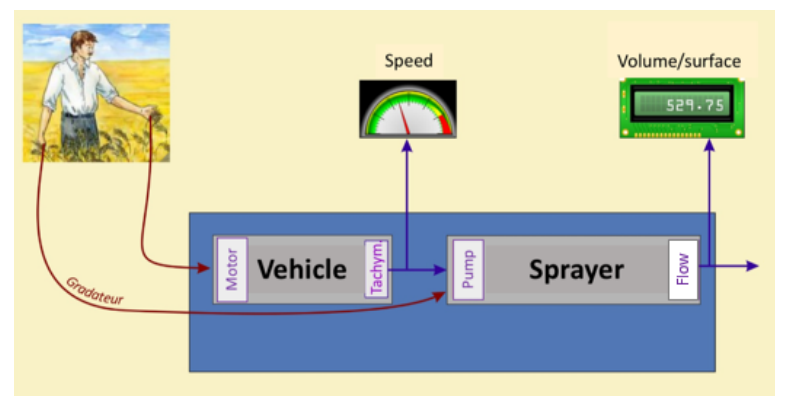

Fig. 16. Navigation aid system embedded in agricultural vehicles

The mission of the system is to follow a predetermined path. To achieve this goal, the system is Geo-localized, manages the movement of the vehicle and detects the potential obstacles on the route. To locate, it treats the data from sensors (GPS for example) allowing its position in real time. To control the movement of the vehicle, it applies trajectory tracking algorithms to send instructions to the actuators (steering wheel, accelerator, brakes). To detect obstacles, it will for instance use a camera or a laser rangefinder. The system communicates with a remote operator so that the latter permanently has a vision of the current activity and the health status of the system. The operator may also remotely change the itinerary and stop the vehicle if necessary.

\section{A. Issues to be addressed and approach}

As it is a project of a small enterprise, the focus is on project management, including an opportunity analysis (added value, distribution policy of the product, positioning of the product on the market, patent filing / managing, etc.).

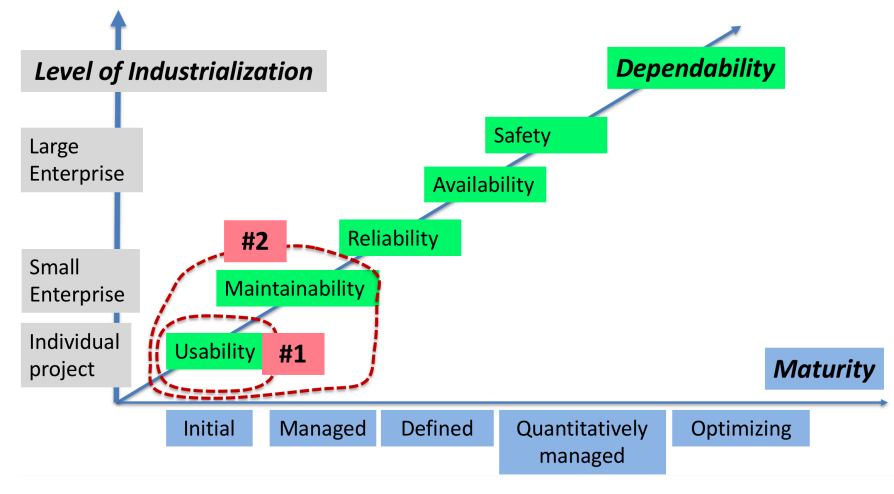


Fig. 17. Learning objectives of the case study $n^{\circ} 2$

As it appears in Fig. 18, development and project management processes are managed, characterized and supervised by standards. The means of production are operational. In terms of dependability, the obsolescence of a component is a key parameter that determines maintainability.

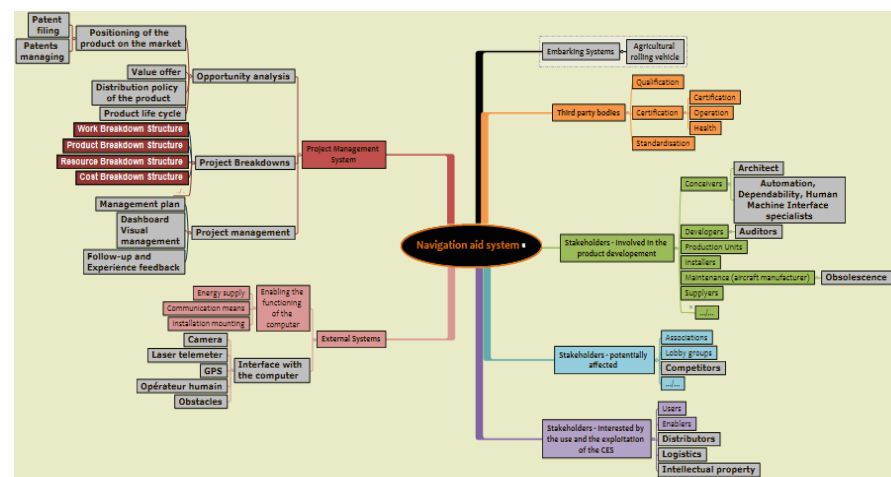

Fig. 18. Context Diagram of aided navigation system embedded in agricultural vehicles

The external systems interfacing with the computer are identified as they impact the design of the computer: GPS, Camera, Human operator, Obstacles of any kind, should it be a child running in the field or a dog, a laser telemeter.

In terms of stakeholders, the small company needs to identify the competitors to differentiate its products in the market. At that point, the evidence of an opportunity analysis appears clearly. It will position the product on the market (without forgetting the patents filing and the patents managing), define the value offer as well as the distribution policy of the product.

The stakeholders interested by the use and the exploitation of the future product (users, enablers, distributors) have to be included from the beginning of the design in order to consolidate the management plan.

This case also offers the pretext to address several specific analyses, such as localization, human-system interactions, and intellectual property.

Geo-localization. The agricultural vehicle must be able to determine its own position with enough precision, within $10 \mathrm{~cm}$ of accuracy, in order to prevent itself from deviating from its trajectory and leaving its field. We propose in this case study a panorama and a comparison of various means of location (rotary encoder, gyroscope, fish sensor, accelerometer, satellite).

Human-system interactions. A human operator must be able to interact with the agricultural vehicle to start-up and initiate configuration, check that it is working properly, program the trajectories to be followed, access the on-board data and stop the vehicle. Different interfaces are examined to ensure and secure these interactions, enabling us to introduce the notions of default values, passwords, self-tests, visual and audible alarms, graphical interfaces, data representation, etc.

Intellectual property. Intellectual property protection mechanisms, such as patents, are based on the fact of granting exclusive rights to creators. Their role is to guarantee the remuneration of creative investment. They cover specific areas: technical inventions and devices, aesthetic aspects, trade names, artistic creations and software. In this case, we address the case of technical devices, including counterfeiting issues, and the case of software and copyright.

Research articles about autonomous agricultural engines and IoT are provided to deepen this case study.

\section{G. Demonstration of the interest of a systemic approach}

This case study makes the trainee discover:

- The development of a non-critical embedded connected systems, with the need to formalize and to manage the processes,

- The raising issues to develop and produce systems in small series (scale-up),

- The resources organization in the company to develop a product,

- The need to formalize and to manage the processes (including maintenance, support operational, withdrawal of service, and addressing the compliance to environmental standards and recycling).

- The quality organization, including qualification issues.

In this case study, multidisciplinary teamwork brings to share specific technical elements from different expertise areas. The members of the team thus expand their own area of expertise while opening to other areas. This way, the trainee learns that, in the domain of human-machine interfaces, the human should always be able to process the information that a system generates and displays; therefore, this information must be contextual, unambiguous and quickly assimilated. More specifically to the case study, we learn to proceed to geolocation, the operational context is essential in the definition of the solution (for example, we will avoid a solution based on airwaves in an urban environment with buildings that can reflect these waves).

Note that we can see the crucial role (integrating and managing processes and disciplines) of the system architect emerging here, and its positioning in projects compared to the project manager (responsible for the project performance objectives). These two roles can be played by one person in a small structure and by different persons in a large company, thus requiring collaborative work.

In terms of Systems Thinking capabilities, the trainees are engaged in this case study to experience the ability of integrate and synthesize the different stakeholders' viewpoints, in order to manage the project, the ability to create and innovate in order to design a new product [18].

\section{CONNECTED EMBEDDED AVIONICS COMPUTER}

The third case study belongs to the civil aviation field.

\section{H. Setting the situation}

Imagine you are an engineer in a service provider company. Your company missions you to develop an embedded system in the field of avionics. Before starting the mission, you need to have a holistic view of the specific environment of avionics embedded systems and their development constraints. 
In this case study the function being considered, consists of improving the comfort of passengers of an airplane during their flight. The system is complex as it uses a sensors network (including accelerometers), flight control computers, digital treatment of signals as well as the control actuators of the surfaces to ensure the passenger comfort, and to control of the surfaces (cf. Fig. 19).

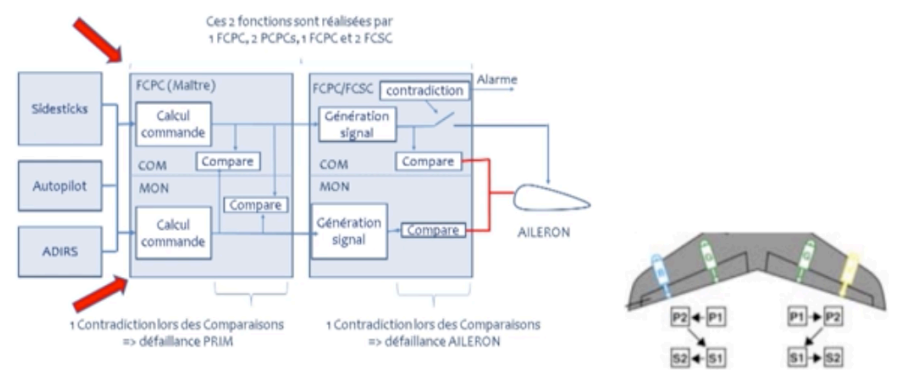

Fig. 19. Case of a complex system in avionics [19]

This system is critical because it may impact not only the safety of the passengers, but also the capabilities of piloting of the pilots as well as the structure of the plane. It must be faulttolerant, to protect itself against a distortion of regulatory procedures, technical failures and human errors, whether voluntary or not [20].

Thus, unlike previous cases where the connected embedded system was firstly addressed by its features, this case study is built from a dependability viewpoint which addresses and drives the whole life cycle of the product as well as the interactions with its users [21].

\section{A. Issues to be addressed and approach}

In this case study, we introduce the issue regarding the development of critical embedded systems on which safety has a very strong impact. Dependability, considered in all its attributes (safety, reliability, availability, maintainability), is crucial and drives the development of the system. It relies on formal specifications and verification, and on the definition of an architecture that meets the requirements validated by the certification authorities. Processes are quantitatively managed, standards-driven and constrained by strict regulation (cf. Fig. 20).

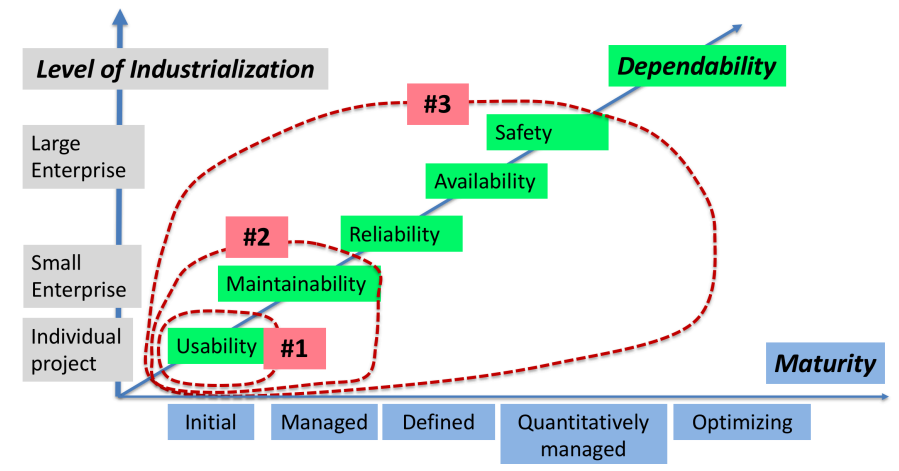

Fig. 20. Learning objectives of the case study $n^{\circ} 3$

This case study highlights the importance of validation \& verification $(\mathrm{V} \& \mathrm{~V})$. On one hand, the $\mathrm{V} \& \mathrm{~V}$ process relies on formal specifications and definition of an architecture that meets the requirements validated by Certification Authorities. The definition of the V\&V means that support the development supports such as simulators, Flight Tests and Ground Tests are defined at a very early stage in the project as they must be operative (or even qualified) in time. Moreover, if they need qualification, they must be accepted by the Certification Authorities early enough in the concept / feasibility stage. The Certification process, which is one of the pillars of Airworthiness, is addressed. Human factors and human machine integration are covered in this case study which addresses the passenger's comfort. Development and project management processes are standards-driven and constrained by regulation. Industrialization is based on specific components which are compliant with Aeronautics standards. The Context Diagram involves the different stakeholders (cf. Fig. 21).

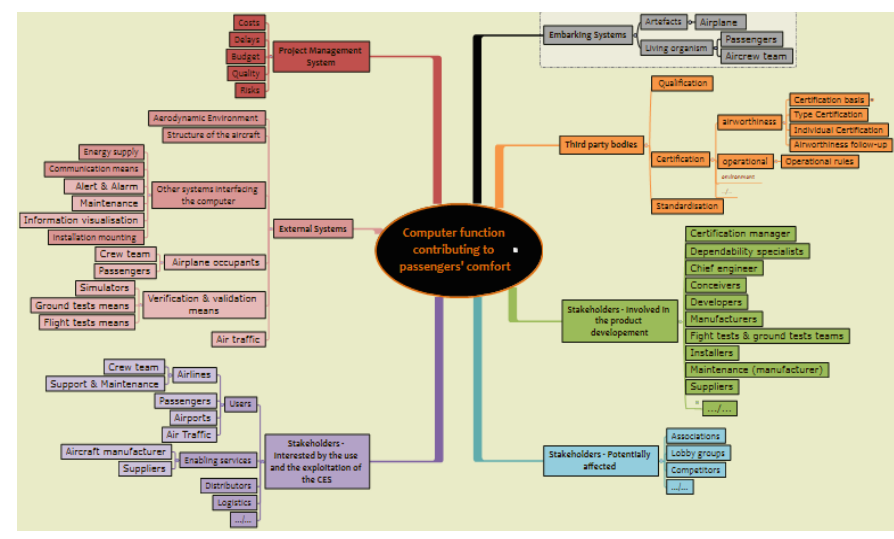

Fig. 21. Context Diagram of a computer function contributing to passenger's comfort.

On the top of the stakeholders already identified in the previous case studies, we point out here the importance of the third parties (Qualification, Standardization, Certification Airworthiness and Operational Authorities), as they have requirements that drive the design and the operation of the product.

Moreover, we point out a new kind of external systems who play a major role in the function of a comfort as they will be "modelized" during the design and development process; we refer to the airplane occupants, team as well as passengers.

This case study lays the ground for several specific analysis, such as the relationships between passengers' comfort and safety, or the means of communication.

Passenger's comfort and safety. In the context of Airworthiness Regulation, "passenger comfort" is one of the three criteria used to evaluate the effect of the so called "Failure conditions" on aircraft and occupants. It is related to the appreciation and evaluation of discomfort, injury or death of occupants. It considers not only physical criteria (injury, shock, death) but also physiological criteria linked to the perception of noise, temperature, light, smell and the perception of the aircraft shaking, etc. As far as flight safety is concerned, whatever the turbulence zone crossed by the plane, it is required to ensure on one hand the integrity of the airplane structure and on the other hand the ability of the crew to pilot as well as the g-tolerance 
level being within the regulated tolerance threshold. This example highlights the complexity of the "passenger comfort" function. It connects and integrates different disciplines that are quite familiar within the aircraft manufacturer disciplines (such as aerodynamics, structure, systems which control the airplane surfaces in turbulent zones), with healthcare and sensory physiology for instance.

Means of communication. We study different types of networks, notably the OSI model and its organization of communication functions, versus the TCP/IP model, the most widespread solution in the world of connected objects. We fully explored two types of standardized networks: the AFDX network (Avionics Full DupleX), a redundant and reliable Ethernet network which is an implementation of the ARINC 664 Part 7 specification, and the DDS network (Data Distribution Services) which is an OMG group standard based on a data exchange technology via a publication/subscription network.

This case study is an illustration of how Systems Engineering is applied in aeronautics. Other resources allow the learners to go further on correlated topics such as response time, project management, engineering standards, integrated logistic support, modeling, certification, etc.

\section{B. Demonstration of the interest of a systemic approach}

The educational goal that arises from this case study is to understand:

- The need to formalize and to manage the processes in accordance with standards and regulatory agencies,

- The organization of the quality,

- Certification and its relationships with dependability requirements, their impact on the development of critical systems.

In terms of Systems Thinking capabilities, the trainees are engaged in this case study to develop the ability to seek for implicit needs (from the customers, for instance), to look for influential factors in the design of the function, the capability to qualify the observations and measure phenomenon [18].

\section{RESULTS}

This section first provides a global assessment of the MOOC results, with a synthesis of feedback from 2016 and 2017 sessions that led to introducing this MOOC in a curriculum of the University of Toulouse. Then it discusses the interest of adopting a pedagogy based on case studies. It finally analyses the knowledge and skills acquired along this MOOC.

\section{A. Feedback from 2016 and 2017 sessions}

The project team made an ambitious bet by launching this MOOC project and success was achieved. This section provides some figures in order to give a general overview of how this MOOC was received.

\section{Format and parameter setting of the MOOC}

For the 2016 session, the MOOC was open over 6 weeks, with a progressive opening of case studies every two weeks or so. The planned evaluation was twofold: a quiz was proposed at the end of each case study, and a final peer-reviewed exercise was to be completed at the end of the MOOC. The validation of the MOOC was done on the average of the two notes.

For the 2017 session, the MOOC was open over 10 weeks, all the modules were available from the opening, allowing everyone to appropriate the concepts discussed at their own pace, own rhythm and independently, and to individualize their course. A pedagogical progression was however suggested so that the learners do not get caught on the last case study to which we deemed necessary to devote at least 3 weeks, following the feedback from the first session. The final peer review was removed to return to a more traditional quiz assessment only, one per case study, with a total of 85 questions. The success threshold was raised in order to compensate for the cancellation of the final exercise.

\section{Learners' profile}

The profile of the participants showed that almost $80 \%$ were active or studying.

From the 2016 session, $80 \%$ had a bachelor level or above (54\% with a master level, 10\% with PhD level). From the 2017 session, $17 \%$ of the participants had a bachelor level, $47 \%$ had a master level and 8\% a PhD level (see Fig. 22).

Level of study (2016) Level of study (2017)
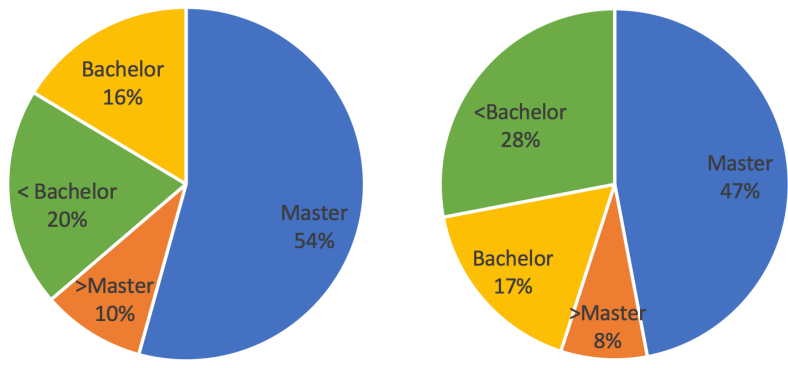

Fig. 22. Repartition of participants according to their level of study

In terms of geographical origin, we notice a majority of French speaking participants, expanded to 71 countries in 2017 session, with a distribution as shown in Fig. 23.

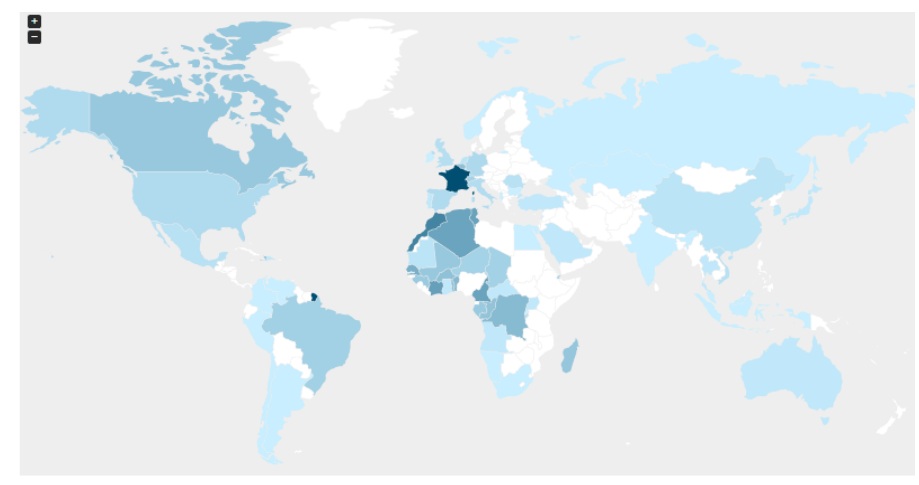




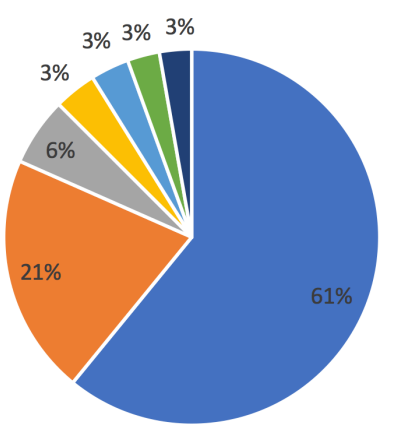

- France

- Unknown

= Marocco

- Algeria

- Cameroon

- Ivory Coast

- Tunisia

Fig. 23. Repartition of participants according to their geographical origin (2017)

In $2016,45 \%$ of the participants were between 19 and 35 years old, $47 \%$ between 36 and 55 years old. There was a slight rejuvenation of participants in 2017.

The registrants were overwhelmingly men, with a rate of $76 \%$, certainly explicable by the scientific and technical field considered.

The estimated level of learners' knowledge of the embedded domain ranged from beginner to intermediate at the first session (see Fig. 24). For the second session, we observed more novices in embedded systems, registered by curiosity.

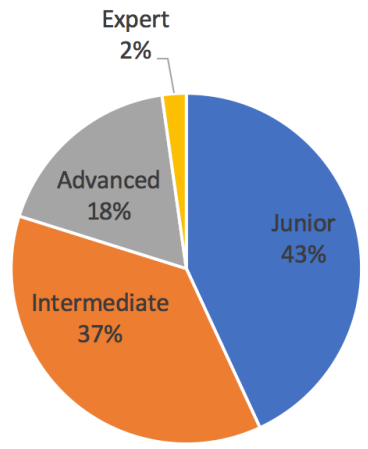

Fig. 24. Repartition of participants according to their level of knowledge of the domain

\section{Time spent learning}

For the first session, the pedagogical team estimated the working time per week at $2 \mathrm{~h} 30$. Participants spent on average 3 hours per week. Some found that classes were dense, especially in the last few weeks, and required more than 4 hours of work per week. The team might have therefore underestimated the workload. The solution chosen for the 2017 session was to open the MOOC over more weeks in order to lighten the workload.

\section{Satisfaction level}

The level of satisfaction was high: $90 \%$ of participants felt they had learned between enough and a lot from the MOOC. $83 \%$ intended to recommend this MOOC. Some comments bear witness to this: "My congratulations and thanks for this MOOC", "The concepts that were discussed were interesting and accessible. The diversity of the speakers and themes is an asset", "A big 'Thank you' to the Toulouse team for this ambitious panorama and for the richness of contributions".

\section{Number of registrations and certificates}

In 2016, the MOOC totaled 4,722 registrations, with 101 certificates issued. In 2017, there were 6,116 registrations and 358 certificates issued, i.e. $5.85 \%$ of registrations, which corresponds to the average follow-up rate for MOOCs.

The rate at which certificates are issued does not necessarily correspond to drop-outs along the way. The reasons can indeed be multiple: some are related to the organization of the MOOC (late registrations - in 2017, 439 were registered after the closing date of the MCQ, level of difficulty, duration of 10 weeks, quality of the learning material, etc.), others are related to the learners profile (time to devote to the required personal work, ability to meet the deadliness, professional situation, level of study, motivation to obtain the certificate, etc.).

\section{B. Introduction of the MOOC in a curriculum}

After two sessions on the FUN platform, the MOOC was introduced as a credit-earning course in a master level curriculum at INSA (the National Institute of Applied Sciences) of Toulouse in 2018. Here we get some feedback from students.

They liked the way the different scientific disciplines, previously approached in their classical curriculum in a compartmentalized way, were put into perspective. This enabled them to give a meaning to their curricula and their training as engineers with regard to a job profile that they can now clearly identify.

The students also liked the diversity of application areas covered by the case studies, which also gave them a societal openness.

Besides, they appreciated the importance of the systemic approach, regretting that it had not been proposed earlier in their curriculum.

The students also appreciated the pedagogical progression. Although the first case study did not raise any major technical difficulties for them, it provided the vocabulary, the concepts, a framework for reflection and analysis, which allowed them to progress in the other case studies and acquire the knowledge they needed to consolidate.

\section{Learning based on case studies}

The method of training chosen in the MOOC, based on case studies, has promoted active learning by the trainees via individual brainstorm but also via the group discussions that took shape throughout the on-line forums.

For the trainees, it contributed to developing their abilities in analysis and problem solving, judgment, critical thinking, sensitiveness to technological, societal, ethical, scientific and economic disciplines related to the field of connected embedded systems. Through a real industrial business situation, it allowed developing not only knowledge, but also and especially know-how and soft skills [22], by an illustration of the attitudes of the system thinker.

Thus, throughout the MOOC, learners have developed their knowledge and know-how, progressing over case studies following three axes: the maturity of the process, the level of industrialization and dependability. 
Fig. 25 summarizes the progress in the studies of cases along the defined three axes: the maturity of the process, the level of industrialization, and the degree of operational safety.

\begin{tabular}{|c|l|l|l|}
\hline \multicolumn{1}{|c|}{ CMMI (*) level } & Industrialization level & \multicolumn{1}{c|}{ Dependability } \\
\hline CASE 1 & $\begin{array}{l}\text { Level 1: processes } \\
\text { unpredictable, poorly } \\
\text { controlled \& reactive } \\
\text { Level 2: processes }\end{array}$ & $\begin{array}{l}\text { Prototype realized by } \\
\text { assembling on shelves } \\
\text { components }\end{array}$ & $\begin{array}{l}\text { Intuitive scenario approach } \\
\text { (mainly relative to utilisability) }\end{array}$ \\
\hline CASE 2 & $\begin{array}{l}\text { Development of an } \\
\text { and often reactive }\end{array}$ & $\begin{array}{l}\text { Dependability focused on } \\
\text { utilisability and maintainability. }\end{array}$ \\
\hline CASE 3 3 in an SME & $\begin{array}{l}\text { Level 4 / 5: processes } \\
\text { measured \& controlled, } \\
\text { potentially focused on } \\
\text { process improvement }\end{array}$ & $\begin{array}{l}\text { Mass production } \\
\text { based on specific } \\
\text { component in an } \\
\text { extended enterprise }\end{array}$ & $\begin{array}{l}\text { All dimensions of dependability } \\
\text { are taken into account (safety, } \\
\text { reliability, availability, } \\
\text { maintainability, usability) }\end{array}$ \\
\hline
\end{tabular}

Fig. 25. Synthesis of the learning progression along three axes

\section{Knowledge, know-how and soft skills acquired}

Systems Thinking demonstrated to the learner the need to adopt a new way of observing a situation in order to extract from it a situation system and a System Of Interest, leading naturally to an interdisciplinary approach - (not only technology focused but also considering societal or regulatory commitments, to name a few), essential to exploring the whole embedded systems field.

Interdisciplinarity is all about getting people from different scientific disciplines to work together. The approach presumes achieving a common goal which requires the confrontation of different viewpoints on the same situation. This approach involves dialogue, exchanges of knowledge, know-how, analysis and methods used by each discipline. It involves strong interactions and mutual enrichment between different specialists, and therefore active cooperation with an awareness of the compromises needed to find possible solutions acceptable to all stakeholders. Interdisciplinarity relies on System Thinker's attitudes such as being able to listen, have open discussion, breakthroughs, disruptions. It is important to integrate disciplines as early as possible in the curricula so as not to repeat this model in industry or in the professional world in order to break the silos of the business units as well.

The implementation of Systems Engineering processes [23] enabled the learners to acquire a method that provides the means to set up a consistent design and management plan that fully integrates a product development.

The exercises and the forums associated with the case studies allowed learners to unveil and develop specific skills to identify and solve problems throughout the case studies.

\section{CONCLUSION}

The goal of this MOOC was to show how the systemic approach allows understanding a complex situation and to characterize the relationships at two levels (Stakeholders and External Systems) when considering the interaction of the environment with the connected embedded systems. It raised notably disciplinary integration and project management issues.

By participating to this MOOC, the participants learned how to approach these systems in a methodological and global way, by forgetting the traditional approach of the disciplines in silos and by opening themselves to societal, economic and legal issues. They are introduced to some of the Systems Thinker's attitudes which can be used in any daily life situation when trying to understand complex situations.

This experience run during two successive years met with a strong success. The pedagogical choices contribute to this success. The MOOC format enabled active learning. The case studies proved to be a stimulating learning and training tool boosting a training anchored on the practice. Last but not least, one of the success factors is certainly due to the fact that the teaching team, challenged by such an ambitious and innovative project, has also experienced a systemic approach to integrate multiple skills and disciplines in a cooperative and collaborative way.

To conclude on adopting a MOOC format to teach, we observed that MOOCs have a lot of potential for reinventing teaching. However, they cannot pretend to replace the teacher, and pedagogy in the future would probably be based on hybrid techniques. This way, Claude Lelièvre, historian of education and professor emeritus in Paris, hopes that "with the Internet and the proliferation of digital textbooks, software tools and MOOCs, formal lectures will disappear to give way to another model, close to reserve pedagogy: the course would be delivered at distance and the face-to-face master-students would be entirely devoted to the application of knowledge, exercises and practical cases" [24].

\section{ACKNOWLEDGMENT}

The article authors thank the MOOC project team, including the pedagogical engineering and production team, and all the contributors to the videos. Our thanks also go to the INP (Polytechnic National Institute) of Toulouse and INSA Toulouse services, as well as the IDEX (Initiatives of Excellence) whose funding has allowed the project off the ground.

\section{REFERENCES}

[1] Embedded System definition, https://fr.wikipedia.org/wiki/Système Embarqué. Consulted 12-12-2017

[2] OPIEC (Observatoire Paritaire Informatique Ingénierie Etudes Conseil). Etude sur l'évolution des métiers et des besoins en formation pour les systèmes embarqués, online, 2014.

[3] Connected Object definition, http://www.mercatorpublicitor.fr/lexique-marketing-definition-objetsconnectes. Consulted 26-12-2017.

[4] Mitchell M., 2009. Complexity A guided tour, Oxford University Press.

[5] http://dictionary.cambridge.org/fr/dictionnaire/anglais/mo oc

[6] Baron et al., MOOC Systèmes Embarqués et Objets Connectés, $2016 . \quad$ https://www.funmooc.fr/courses/course-v1:univtoulouse $+101001+$ session02/about

[7] Daniel-Allegro B., 2014a. Introduction au Penser Système. Séminaire AFIS - INSA du 20-11-2014. http://pensersysteme.fr/

[8] Meinadier J-P., 2012. AFIS Découvrir et Comprendre l'Ingénierie Système. Sous la direction de Serge Fiorèse et de Jean-Pierre Meinadier. Ed. Cépadues 
[9] Checkland, P. 1999. Systems Thinking, Systems Practice. New York, NY, USA: John Wiley \& Sons.

[10] E. Weil, Pratique et Praxis, Encyclopædia Universalis [on line], consulted 2018/06/30. http://www.universalis.fr/encyclopedie/pratique-et-praxis/

[11] A joint effort of INCOSE, ISSS, IFSR (Collective). 2012. Sixteenth IFSR Conversation. http://systemspraxis.org/

[12] [Daniel-Allegro, 2014b] Daniel-Allegro B., 2014. AFIS Guide d'introduction au Penser Système. Sous la coordination de B. Daniel Allegro, A. Le Put et J-C. Tucoulou.

[13] Daniel-Allegro B., with the support of Lawson, 2014. Attaining a System perspective. EMEA Systems Engineering Conference 2014. Tutorial $n^{\circ} 29$.

[14] Hitchins, D. 2007. Systems Engineering: A 21st Century Systems Methodology. Hoboken, NJ, USA: John Wiley \& Sons.

[15] ISO/IEC/IEEE 15288, 2015. Systems and software engineering - System life cycle processes.

[16] Jackson, S., D. Hitchins, and H. Eisner. 2010. "What is the Systems Approach?". INCOSE Insight. 13(1): 41-43.

[17] Lawson, H., 2010. A Journey Through the Systems Landscape, London, UK: College Publications, Kings College, translated by Daniel-Allegro B., 2014. Parcours au Pays des Systèmes, College Publications.

[18] Daniel-Allegro B., Gary Robert Smith, 2016. Exploring the branches of the Sytems Landscape, Les éditions Allegro Brigitte D.

[19] Haouati M. S., 2010. Architectures innovantes de systèmes de commandes de vol. Thèse de Doctorat Institut National Polytechnique de Toulouse.

[20] EUROCAE ED-79A, 2009. Guidelines for development of civil aircraft and systems.

[21] ARP4761 / ED135, 1996. Guidelines and Methods for Conducting the Safety Assessment Process on Civil Airborne Systems and Equipment.

[22] Barnes L. B., Christensen C.R., Hansen A., 1994. Teaching and the Case Method. Harvard Business School Press.

[23] INCOSE, 2011. Systems Engineering Handbook. A guide for system life cycle processes and activities. INCOSE TP- 2003-002.03.2.2

[24] [Monde, 2014] supplément « Culture et Idées » du numéro du 30 août 2014 du journal Le Monde. 